\title{
Interpretation of arterial blood gases
}

\author{
CP Dokwal
}

\begin{abstract}
Measuring arterial blood gas is routinely performed in critically ill patients, and may unravel severe life-threatening acidbase disorders or hypoxemia. It provides the vital information about ventilation, oxygenation, and acid-base status in such persons. These three processes are intimately related to each other in achieving normal oxygenation and acidbalance in the body.

The interpretation of arterial blood gas requires a reasonable understanding of respiratory physiology and acid-base balance in the body. Hence, in the following section, first the role of alveolar ventilation, oxygenation, and the maintenance of acid-base homeostasis have been discussed. This is followed by a step-wise approach to analyze the acidbase disorders, if present.
\end{abstract}

The Arterial blood gas (ABG) measurement is performed in most patients admitted to intensive care units. It provides vital information about adequacy of oxygenation and acid-base homeostasis. Adequate ventilation is important not only for normal arterial oxygen tension $\left(\mathrm{PaO}_{2}\right)$, but also for the normal arterial $\mathrm{CO}_{2}$ tension $\left(\mathrm{PaCO}_{2}\right)$. The measurement of $\mathrm{pH}$ states whether an acidemia (low $\mathrm{pH}$ ) or alkalemia (high $\mathrm{pH}$ ) is present.

The body is continuously producing acids as a byproduct of metabolism. About $1 \mathrm{mEq} / \mathrm{Kg}$ body weight of "fixed" or "non-volatile" acids (sulfuric acid, phosphoric acids, and other organic acids) are formed daily from the metabolism of dietary proteins (Kurtz et al, 1983) which are excreted through the kidneys. In addition, the body also produces $\mathrm{CO}_{2}$ through the oxidative metabolism, which is eliminated by the lungs.

Thus, it is important that the arterial blood gases and $\mathrm{pH}$ are maintained within a narrow normal range. This is achieved by the close interaction of three basic processes, namely ventilation, oxygenation, and acid-base homeostasis. Before attempting to interpret the ABG, it is important to understand the role they play in maintaining the $A B G$ values within the normal range.

\section{Alveolar ventilation}

The body produces about 15,000 to $20,000 \mathrm{mmol}$ of $\mathrm{CO}_{2}$ per day. About $90 \%$ of $\mathrm{CO}_{2}$ is carried in the blood as $\mathrm{HCO}_{3}$, about $5 \%$ as dissolved form, and the remaining $\mathrm{CO}_{2}$ in the combination with hemoglobin. The $\mathrm{CO}_{2}$ is ultimately carried to the lungs from where it is excreted. The measurement of $\mathrm{PaCO}_{2}$ reflects the ratio of metabolic $\mathrm{CO}_{2}$ production to alveolar ventilation. The relationship of $\mathrm{CO}_{2}$ and $\mathrm{VCO}_{2}$ is shown by the $\mathrm{PaCO}_{2}$ equation

$$
\mathrm{PaCO}_{2}=\mathrm{VCO}_{2} \times 0.863 / \mathrm{VA}
$$

(where $\mathrm{PaCO}_{2}$ is the partial pressure of dissolved $\mathrm{CO}_{2}$ in blood, $\mathrm{VCO}_{2}$ is the amount of $\mathrm{CO}_{2}$ produced per minute, $\mathrm{VA}$ is alveolar ventilation (i.e. minute ventilation - dead space ventilation).

Thus, in case of alveolar hypoventilation due to any cause or ventilation/perfusion [V/Q] imbalance, the $\mathrm{PaCO}_{2}$ increases (hypercapnia), whereas in hyperventilation its value decreases (hypocapnia). An elevated $\mathrm{PaCO}_{2}$ value also lowers the $\mathrm{PaO}_{2}$ by decreasing the partial pressure of oxygen in alveolar air $\left(\mathrm{PAO}_{2}\right)$ (as explained in alveolar gas equation later), and lowers the $\mathrm{pH}$.

\section{Oxygenation}

The maintenance of normal partial pressure of oxygen in arterial blood $\left(\mathrm{PaO}_{2}\right)$ is vital for survival. This is achieved by diffusion of oxygen across the alveolar membrane:

\section{(a) The diffusion of oxygen across the alveoli}

The rate of diffusion of $\mathrm{O}_{2}$ across the alveoli depends upon the partial pressure of oxygen in the alveolar air $\left(\mathrm{PAO}_{2}\right)$. The $\mathrm{PAO}_{2}$ is always higher than the arterial $\mathrm{PO}_{2}\left(\mathrm{PaO}_{2}\right)$, This difference of partial pressure of oxygen between alveoli and arterial blood is denoted as $\mathrm{PAO}_{2}-\mathrm{PaO}_{2}$, or simply as $\mathrm{P}(\mathrm{A}-\mathrm{a}) \mathrm{O}_{2}$, and this is the driving pressure for diffusion of oxygen across the alveolar membrane. The relationship between $\mathrm{PaO}_{2}$ and $\mathrm{PAO}_{2}$ is derived from the simplified alveolar air equation as shown below.

$$
\mathrm{PAO}_{2}=\mathrm{PIO}_{2}-1.2\left(\mathrm{PaCO}_{2}\right)
$$

(Where $\mathrm{PAO}_{2}$ is the average alveolar $\mathrm{PO}_{2} ; \mathrm{PIO}_{2}$ is the partial pressure of inspired oxygen in trachea. In this equation, the multiplication factor "1.2" is dropped when $\mathrm{FIO}_{2}$ exceeds $60 \%$ ).

$$
\mathrm{PIO}_{2}=\mathrm{FIO}_{2}(\mathrm{~PB}-47)
$$

(Where $\mathrm{FIO}_{2}$ is the fraction of inspired oxygen and $\mathrm{PB}$ is the barometric pressure of $760 \mathrm{~mm} \mathrm{Hg}$; and water vapor pressure at normal body temperature is 47 ).

The normal $\mathrm{P}(\mathrm{A}-\mathrm{a}) \mathrm{O}_{2}$ difference is due to a normal amount of ventilation/perfusion (V/Q) imbalance in the human lung which happens due to the gravity-related blood flow changes within the lungs. The normal value of $\mathrm{P}(\mathrm{A}-\mathrm{a}) \mathrm{O}_{2}$ ranges between 5 to $10 \mathrm{~mm} \mathrm{Hg}$ in a person breathing room air, although it tends to increase with age, and a value even as high as $20 \mathrm{~mm} \mathrm{Hg}$ is considered normal in an $80 \mathrm{yr}$ old person.

It is easy to understand that hypoxemia can occur either due to alveolar hypoventilation or ventilation/perfusion 


\section{Interpretation of arterial blood gases}

(V/Q) mismatch in the lung. The increased V/Q mismatch is the commonest cause of hypoxemia in ICUs. Hypoventilation accounts for hypoxemia in cases in whom either the respiratory centre is severe depressed or the respiratory pump failure is present. Rarely, it may be due to low $\mathrm{PAO}_{2}$ as at high-altitude.

Hypoxemia should always be interpreted on the basis of the $\mathrm{P}(\mathrm{A}-\mathrm{a}) \mathrm{O}_{2}$ value. The increased $\mathrm{P}(\mathrm{A}-\mathrm{a}) \mathrm{O}_{2}$ value is seen in conditions as in pneumonia, atelectasis, asthma, interstitial lung disease or pulmonary edema. The increased $\mathrm{P}(\mathrm{A}-\mathrm{a}) \mathrm{O}_{2}$ is also seen in right-to-left cardiac shunts.

Hypoxemia associated with normal $\mathrm{P}(\mathrm{A}-\mathrm{a}) \mathrm{O}_{2}$ is seen in hypoventilation such as drug overdose, coma, CNS depression, and sufficient respiratory muscle weakness due to any cause.

\section{(b) The oxygen content of the blood}

The oxygen is carried in the blood in two forms, the combined form with hemoglobin, and as a dissolved gas in the plasma. Most of the oxygen is carried in a chemically combined form with hemoglobin, whereas the dissolved form constitutes a very minute amount of the total oxygen content of the blood. One gram of hemoglobin, when fully saturated, combines with $1.34 \mathrm{ml}$ of oxygen. Thus, a person with hemoglobin of $15 \mathrm{gm} \%$ will carry $15 \times 1.34=$ $20.1 \mathrm{ml}$ of oxygen as carbamino compounds, whereas it will contain only $0.3 \mathrm{ml}$ of oxygen in dissolved form, when the hemoglobin is fully saturated. The oxygen content can be measured directly or calculated by the oxygen content equation as shown here:

$$
\mathrm{CaO}_{2}=\left(\mathrm{Hb} \times 1.34 \times \mathrm{SaO}_{2}\right)+\left(.003 \times \mathrm{PaO}_{2}\right)
$$

(where $\mathrm{Hb}$ is in $\mathrm{gm} \% ; \mathrm{SaO}_{2}$ is percent saturation of hemoglobin with oxygen; and .003 is the solubility coefficient of oxygen in the plasma)

Here, it is also important to understand the oxyhemoglobin desaturation curve. As per this curve, at $\mathrm{PaO}_{2}$ of $60 \mathrm{~mm}$ $\mathrm{Hg}$, the hemoglobin is $90 \%$ saturated, and the oxygen content of blood is very close to normal values. Thus in critically ill patients, one should not try to achieve a higher $\mathrm{SaO}_{2}>92 \%$, if a patient needs an $\mathrm{FIO}_{2}>0.6$ for a prolonged period.

\section{Acid-base balance}

The blood $\mathrm{pH}$ is maintained within a normal range through the interaction of blood buffers, lungs, and kidneys. The buffer systems include both bases and acids in the blood, which act instantaneously to prevent the change in $\mathrm{pH}$. The lungs take few minutes, whereas the kidneys take a much longer time, usually 3 to 5 days to bring $\mathrm{pH}$ to normal.

The $\mathrm{pH}$ primarily depends upon the ratio of $\mathrm{HCO}_{3}^{-}$to $\mathrm{H}_{2} \mathrm{CO}_{3}$ as shown in the Henderson-Hasselbalch equation,

$$
\mathrm{pH}=\mathrm{pK}+\log \left(\mathrm{HCO}_{3} \% .03 \times \mathrm{PaCO}_{2}\right)
$$

(where the value of the constant $\mathrm{pK}$ is 6.4).

The acid-base disorders are primarily classified into metabolic and respiratory disorders, which are further subclassified as acidosis or alkalosis depending upon whether $\mathrm{PaCO}_{2}$ or $\mathrm{HCO}_{3}^{-}$is primarily affected. Acidemia is said to be present when the blood $\mathrm{pH}$ is less than 7.35, whereas, in alkalemia the $\mathrm{pH}$ is more than 7.45. The underlying processes causing acidemia and alkalemia are known as acidosis or alkalosis, respectively. It should be remembered that two or more acid-base disturbances can concurrently exit, for example, respiratory acidosis with metabolic alkalosis, or metabolic acidosis or alkalosis with another metabolic or respiratory disturbance.

\section{(a) Respiratory acidosis}

In respiratory acidosis, the increase in the $\mathrm{PaCO}_{2}$ causes a fall in $\mathrm{pH}$. Hypercapnia results when the $\mathrm{PaCO}_{2}$ is more than $45 \mathrm{~mm} \mathrm{Hg}$, and is seen when the $\mathrm{CO}_{2}$ excretion by lungs lags behind $\mathrm{CO}_{2}$ production, resulting in positive $\mathrm{CO}_{2}$ balance (Adrouge and Madias, 1998). It is mainly caused by hypoventilation or a severely low V/Q mismatch.

The $\mathrm{CO}_{2}$ molecule is more lipid soluble than $\mathrm{H}^{+}$, hence respiratory acid-base changes (acidosis or alkalosis) equilibrate across cell membrane far more rapidly than do primary metabolic acid-base changes (Laffey and Kavannah, 2009). Moreover, higher the base-line $\mathrm{PaCO}_{2}$, the greater will be the rise in its value for a given fall in alveolar ventilation even when $\mathrm{CO}_{2}$ production remains unchanged.

In acute hypercapnia, the plasma $\mathrm{HCO}_{3}{ }^{-}$concentration rises mainly by the $\mathrm{HCO}_{3}{ }^{+}-\mathrm{Cl}^{-}$shift in the $\mathrm{RBCs}$, and it increases by $1 \mathrm{mEq} / \mathrm{L}$ for each $10 \mathrm{~mm} \mathrm{Hg}$ rise in $\mathrm{PaCO}_{2}$. However, in chronic respiratory acidosis, the increase in plasma $\mathrm{HCO}_{3}$ is due to renal compensatory mechanism, and the rise is much higher (see table no. 1).

\section{(b) Respiratory alkalosis}

$\mathrm{PaCO}_{2}$ represents the balance between the production and elimination of $\mathrm{CO}_{2}$, and is maintained within a narrow physiologic range (Laffey and Kavanagh, 2009). A decrease in $\mathrm{PaCO}_{2}$ increases the blood $\mathrm{pH}$ as defined by Handerson-Hasselbalch equation. Hypocapnia occurs when $\mathrm{PaCO}_{2}$ is less than $35 \mathrm{~mm}$ of $\mathrm{Hg}$, and it primarily reflects the rate of elimination of $\mathrm{CO}_{2}$. Thus, the principal physiologic causes of hypocapnia, including pregnancy are related to hyperventilation (Lafey and Kavanagh, 2009). However, a temporary induction of hypocapnia is a potential life-saving strategy adopted in severe intracranial hypertension or neonatal pulmonary artery hypertension.

Hyperventilation is the main mechanism causing hypocapnia, as commonly seen in asthma, interstitial lung disease, or pulmonary edema. It is also a physiological response in metabolic acidosis of any cause contributing to 


\section{Interpretation of arterial blood gases}

a low $\mathrm{PaCO}_{2}$ as discussed later in this article. Some drugs, particularly salicylates, xanthines, progesterone and beta- 2 agonists cause hyperventilation by stimulating the respiratory centre. Moreover, hyperventilation is also commonly seen in fever, sepsis, and late stages of pregnancy. Some CNS conditions, particularly infections and tumors, may cause hypeventilation.

In respiratory alkalosis, there is a $\mathrm{CO}_{2}$ wash out due to hyperventilation resulting in a low $\mathrm{PaCO}_{2}$. Hence to maintain $\mathrm{pH}$, the kidneys excrete more $\mathrm{HCO}_{3}$. However, the renal compensation is a slow process and takes a few days to minimize the $\mathrm{pH}$ changes. The blood $\mathrm{pH}$ rarely exceed 7.55 in most cases of respiratory alkalosis, however marked alkalemia can be observed with inappropriately set ventilators, some psychiatric conditions, and some lesions of CNS (Adrogue and Madias, 1998).

\section{(c) Metabolic acidosis}

The metabolic acidosis results from either loss of bicarbonate or addition of strong $\operatorname{acid}(s)$ in the extracellular fluids. When an acid enters the plasma, it is neutralized by the blood buffers, including bicarbonate, and this results in a fall in serum $\mathrm{HCO}_{3}^{-}$concentration and $\mathrm{pH}$. An arterial $\mathrm{pH}<6.8$ is often associated with death, although, lower $\mathrm{pH}$ values than this have been reported in few patients who survived.

The acute metabolic acidosis leads to hyperventilation which decreases the $\mathrm{CO}_{2}$ level within a short time and brings $\mathrm{pH}$ towards normal. However, the $\mathrm{PaCO}_{2}$ level usually does not fall lower than $10 \mathrm{~mm} \mathrm{Hg}$, even in severely acidotic patients (Fulop, 1998).

A complete understanding of acidosis will require the calculation of anion gap (AG). The metabolic acidosis is classified as increased anion gap acidosis, or a normal anionic gap (hyperchloremic) acidosis.

\section{(i) Anion gap (AG)}

The AG is the difference between the plasma concentration of major cations and anions. Conventionally, it is calculated as the difference between $\mathrm{Na}^{+}$and the sum of $\left(\mathrm{Cl}^{-}+\mathrm{HCO}_{3}^{-}\right)$. The normal value of AG is $8-14 \mathrm{mEq} / \mathrm{L}$.

$$
\text { Anion gap (AG) }=\mathrm{Na}^{+}-\left(\mathrm{Cl}^{-}+\mathrm{HCO}_{3}{ }^{-}\right)
$$

As the total number of cations in the plasma is always equal to that of anions to maintain the electroneutrality, the AG represents the unmeasured anions in the plasma (Emmett and Narins, 1977), and it primarily includes albumin, phosphate, sulfate, and organic acids (Rastegar, 2007). Most of the normal AG is due to albumin, and the normal AG will be smaller in hypoalbuminemia. As each gram \% of albumin contributes $2.5 \mathrm{mEq} / \mathrm{L}$ to the $A G$, it should be corrected for the serum albumin concentration (Figge and Jabor, 1998). A low anion gap is also seen in halide (Bromide or iodide) intoxication, and multiple myeloma with cationic IgG paraproteinemia.
An increased AG almost always indicates metabolic acidosis. The most common cause of increased $A G$ acidosis is due to addition of strong acids into the plasma, as in diabetic ketoacidosis, lactic acidosis, or alcoholic acidosis. Poisoning with salicylates, ethylene glycol, methanol, formaldehyde, or paraldehyde also causes increased AG acidosis. However, salicylate stimulates respiratory centre causing hyperventilation, thus respiratory alkalosis gets superadded to the primary metabolic acidosis. In chronic renal failure, the excretion of acids through kidneys is reduced causing an increase in AG. However, an increased AG may sometimes also be seen in alkalemia because of an increase in the net ionic charge on plasma proteins, and in dehydration because of increased serum protein concentration.

The hyperchloremic acidosis is caused by renal tubular acidosis or loss of $\mathrm{HCO}_{3}^{-}$from the gastrointestinal tract. Here, the $\mathrm{Cl}^{-}$ions replace the $\mathrm{HCO}_{3}^{-}$ions lost in buffering $\mathrm{H}^{+}$ions to maintain electroneutrality. Renal causes for this condition include renal tubular acidosis type I, II, and IV, and chronic renal failure with GFR $>15-20 \mathrm{ml} / \mathrm{min}$. The extra-renal causes for normal AG acidosis include diarrhea, pancreatic, and biliary fistulas.

\section{(ii) Osmolar Gap}

In some conditions of increased AG metabolic acidosis, the estimation of osmolar gap may uncover the presence of osmotically active substances. However, it should be used cautiously because osmolar gap have poor positive predictive value and negative predictive value, and are not considered good screening tests for toxic alcohol poisoning. In patients with excessively elevated osmolar gap, the presence of toxic alcohols should be confirmed by the laboratory methods.

The osmolar gap is defined as the difference between the measured osmolality and the calculated osmolarity. The osmolality is measured in the laboratory, whereas the calculated osmolarity uses the concentrations of sodium, glucose and blood urea nitrogen.

Osmolar gap $=$ measured osmolality - calculated osmolarity Calculated osmolarity $=2\left[\mathrm{Na}^{+}\right]+$glucose $\left./ 18+\mathrm{BUN} / \mathbf{2 . 8}\right)$

The normal osmolar gap is less than 10. An increased osmolar gap indicates the presence of unmeasured osmoles, as seen in poisoning with methanol, ethylene glycol, paraldehyde, and isopropyl alcohol. Although mannitol increases serum osmolarity transiently, it does not have any effect on metabolic homeostasis.

\section{(iii) The Delta Ratio ( $\left.\triangle \mathrm{AG} / \Delta \mathrm{HCO}^{-}\right) \mathrm{Gap}$}

The delta ratio may help in the assessment of increased $A G$ metabolic acidosis to determine if a mixed acid-base disturbance is present. It is defined as the ratio of increased AG to increased bicarbonate concentration. 


\section{Interpretation of arterial blood gases}

\begin{abstract}
Delta ratio $=\Delta$ Anion gap $/ \Delta \mathrm{HCO}^{-}$
(where $\Delta$ Anion gap is the difference between the measured $\mathrm{AG}$ and the normal $\mathrm{AG}$, and $\Delta \mathrm{HCO}^{-}{ }_{3}$ is the difference between the normal bicarbonate and the measured bicarbonate).

When a strong acid is added to plasma, it is neutralized by both bicarbonate and non-bicarbonate buffers present in extra- and intracellular compartments, resulting in a fall in serum $\mathrm{HCO}_{3}$ and a rise in the anion gap (Rastegar, 2007). However, most of the excess anions remain in the extracellualr fluids. Hence the increase in AG usually exceeds the fall in plasma $\mathrm{HCO}_{3}^{-}$.
\end{abstract}

A delta ratio between 1 to 2 is seen in pure AG metabolic acidosis, however, in diabetic ketoacidosis, the excess ketones are excreted in the urine lowering the $A G$, and decreasing the effect of intracellular buffering, thus the delta ratio is close to $1: 1$. In lactic acidosis an average delta ratio is around 1.6. A delta ratio $<1$ is seen in both high $\mathrm{AG}$ and normal AG metabolic acidosis. A delta ratio $<0.4$ is usually seen in hyperchloremic acidosis. A delta ratio $>$ 2 is seen in high AG metabolic acidosis with a concurrent metabolic alkalosis or a pre-existing compensated respiratory acidosis.

\section{(d) Metabolic alkalosis}

Metabolic alkalosis is common in hospitalized patients (Hodgkin et al, 1980). It occurs when there is a net accumulation of base within or the loss of acid from the plasma, which manifests with an increase in the blood $\mathrm{pH}$ and plasma bicarbonate. The metabolic alkalosis has a depressant effect on respiratory centre causing hypoventilation and a resultant increase in $\mathrm{PaCO}_{2}$. Normally $\mathrm{PaCO}_{2}$ increases by 0.5 to $0.7 \mathrm{~mm} \mathrm{Hg}$ for every $1 \mathrm{mEq} / \mathrm{L}$ rise in plasma bicarbonate concentration (Javaheri and Kazemi, 1987). However, $\mathrm{PaCO}_{2}$ rarely increases more than $60 \mathrm{~mm} \mathrm{Hg}$ purely as a compensatory mechanism even in a severe metabolic alkalosis.

It is commonly caused whenever excessive chloride ions are lost from the gut, kidney, or skin, such as in vomiting, diuretic therapy, and nasogastric suctioning (Galla, 2000). It is also commonly caused by conditions where potassium is depleted in the body, as in primary or secondary mineralocorticoid excess. Chronic milk-alkali syndrome is now rarely a cause of metabolic alkalosis. The drugs, penicillin, carbenicillin, and ampicillin have also been implicated for this disturbnance. It is also seen after the successful treatment of ketoacidosis or lactic acidosis, as these anions are later metabolized to bicarbonate (Galla, 2000).

\section{Compensation in acid-base disorders}

As stressed earlier, the $\mathrm{pH}$ is maintained within a narrow range under physiologic conditions. According to the Henderson-Hasselbalch equation, the $\mathrm{pH}$ mainly depends upon the ratio of $\mathrm{HCO}_{3}^{-} / \mathrm{H}_{2} \mathrm{CO}_{3}$. Hence, an increase in $\mathrm{HCO}_{3}^{-}$is accompanied by a corresponding increase in $\mathrm{PaCO}_{2}\left(\mathrm{H}_{2} \mathrm{CO}_{3}\right)$ value, and vice versa. The respiratory compensation for metabolic derangements is rapid, but the kidneys take about 3 to 5 days to compensate for respiratory disturbances. The table no. 1 shows the corresponding compensatory changes in various types of acid-base disorders.

\section{Steps for interpretation of $A B G s$}

A clinical history and physical examination is important before attempting to interpret the arterial blood gas (ABG) for acid-base balance. The three important values in an ABG, namely $\mathrm{pH}, \mathrm{PaCO}_{2}$, and $\mathrm{HCO}^{-}{ }_{3}$ will indicate the likely acid-base disorders, if present. One must also calculate the likely compensatory changes expected in the patient as shown in Table no. 1. If the compensatory changes are beyond the expected range, an additional acidbase disorder should be suspected. A systemic approach while interpreting $A B G$ is necessary to unravel the acidbase disorders. And finally, $\mathrm{PaO}_{2}$ will identify hypoxemic state, if present, and in a patient receiving mechanical ventilator, it is vital to check $\mathrm{PaO}_{2}$ to check the adequacy of ventilator settings.

(1) First, look at the arterial $\mathrm{pH}$. It will suggest whether an academia $(\mathrm{pH}<7.35)$ or alkalemia $(\mathrm{pH}>7.45)$ is present. However, in the presence of mixed acid-base disorder, the $\mathrm{pH}$ may be normal, e.g. a patient with COPD with respiratory acidosis may also develop metabolic alkalosis

Table no. 1. Compensatory changes in acid-base imbalances

\begin{tabular}{|l|l|}
\hline Primary acid-base disorder & Compensatory changes \\
\hline Acute respiratory acidosis & For every $10 \mathrm{~mm} \mathrm{Hg}$ rise in $\mathrm{PaCO}_{2}$, the $\mathrm{HCO}_{3}{ }^{-}$increases by $1 \mathrm{mEq} / \mathrm{L}$ \\
\hline Chronic respiratory acidosis & $\begin{array}{l}\text { For every } 10 \mathrm{~mm} \mathrm{Hg} \text { rise in } \mathrm{PaCO}_{2}, \text { the } \mathrm{HCO}_{3}{ }^{-} \text {increases by } 3.5 \\
\mathrm{mEq} / \mathrm{L}\end{array}$ \\
\hline Acute respiratory alkalosis & For every $10 \mathrm{~mm} \mathrm{Hg}$ fall in $\mathrm{PaCO}_{2}$, the $\mathrm{HCO}_{3}{ }^{-}$decreases by $2 \mathrm{mEq} / \mathrm{L}$ \\
\hline Chronic respiratory alkalosis & For every $10 \mathrm{~mm} \mathrm{Hg}$ fall in $\mathrm{PaCO}_{2}$, the $\mathrm{HCO}_{3}{ }^{-}$decreases by $5 \mathrm{mEq} / \mathrm{L}$ \\
\hline Metabolic acidosis & $\begin{array}{l}\text { For each } 1 \mathrm{mEq} / \mathrm{L} \text { fall in } \mathrm{HCO}_{3}{ }^{-} \text {, the } \mathrm{PaCO}_{2} \text { decreases by } 1.2 \mathrm{~mm} \mathrm{Hg}, \\
\text { or } \\
\mathrm{PaCO}_{2}=\mathrm{HCO}_{3}{ }^{-}+15, \text { or } \\
\mathrm{PaCO}_{2}=1.5\left(\mathrm{HCO}_{3}^{-}\right)+8 \text { (Winter's formula) }\end{array}$ \\
\hline Metabolic alkalosis & For each $1 \mathrm{mEq}^{-} \mathrm{L} \mathrm{HCO}_{3}^{-}$increase, the $\mathrm{PaCO}_{2}$ increases by $0.7 \mathrm{~mm} \mathrm{Hg}$ \\
\hline
\end{tabular}




\section{Interpretation of arterial blood gases}

due to diuretic use, and as a result may have a lesser fall in $\mathrm{pH}$ than expected.

(2) Next, check the $\mathrm{PaCO}_{2}$ and $\mathrm{HCO}_{3}^{-}$values, and determine if the disturbance is respiratory or metabolic. A low $\mathrm{HCO}_{3}^{-}$will suggest metabolic acidosis, whereas a high $\mathrm{PaCO}_{2}$ will indicate the presence of respiratory acidosis. In other words, in primary respiratory disturbances the $\mathrm{pH}$ and $\mathrm{PaCO}_{2}$ change in opposite directions, whereas in metabolic disturbances they change in the same direction.

(3) Next, check the level of compensation as shown in the Table no. 1. and determine if the compensation is appropriate for the primary disturbance. If it is not so, it is likely that more than one acid-base disturbance is present. Remember that body can not overcompensate in order to normalize the $\mathrm{pH}$. A normal $\mathrm{pH}$ in a patient with acid-base disorder usually indicates a mixed disorder.

(4) Calculate the anion gap (AG), if metabolic acidosis is suspected. Make for if albuminemia is present as discussed earlier. An AG more than $20 \mathrm{mEq} / 1$ strongly indicates an anion gap metabolic acidosis. Sometimes an increased AG may be the only clue to a metabolic acidosis. If the cause of increased AG is not obvious (for example absence of lactic acidosis, diabetic ketoacidosis, or renal impairment) and the ingestion of some toxic material is suspected, calculate the osmolar gap as discussed earlier.

(5) In presence of increased AG, calculate the delta ratio
$\left(\Delta \mathrm{AG} / \Delta \mathrm{HCO}^{-}{ }_{3}\right)$. In an uncomplicated $\mathrm{AG}$ metabolic acidosis, it is between 1 and 2 . A value of delta ratio outside this range suggests the presence of another metabolic disturbance. The delta ratio $<1$ indicates the presence of a simultaneous non-AG metabolic acidosis, whereas a delta raio $>2$ indicates the presence of a metabolic alkalosis too.

(6) Finally check the $\mathrm{PaO}_{2}$ in relation to the inspired oxygen concentration $\left(\mathrm{FIO}_{2}\right)$ as discussed in alveolar air equation. In acute lung injury (ALI) the ratio $\mathrm{PaO}_{2} / \mathrm{FIO}_{2}<$ 300 , and in ARDS it is $<200$.

\section{References:}

1. Adrouge $\mathrm{HJ}$ and Madias NE. Management of life-threatening acid-base disorders. N Engl J Med. 1998;338:26-34 \& 107-111.

2. Asghar R. Use of the $\Delta \mathrm{AG} / \Delta \mathrm{HCO}_{3}-$ ration in the diagnosis of mixed acid-base disorders. J Am Soc Nephrol. 2007;18:2429-2431.

3. Emmett $M$ and Narins R. Clinical use of the anion gap. Medicine 1977:56:38-54

4. Figge J, Jabor A, Kazda A, Fencl V. Anion gap and hypoalbuminemia Crit Care Med. 1998;26:1807-1810.

5. Galla JH. Metabolic alkalosis. J Am Soc Nephrol. 2000;11:369-375

6. Hodgkin JE, Soeprono FF, Chan DM. Incidence of metabolic alkalemia in hospitalized patients. Crit Care Med. 1980;8:725-732.

7. Javaheri S, Kazemi H. Metabolic alkalosis and hypoventilation in humans. Am Rev respire Dis. 1987;136:1101-16.

8. Kurtz I, Maher T, Hulter HN. Effect of diet on plasma acid-base composition in normal humans. Kidney Int. 24:670-680

9. Laffey JG, Kavanagh BP. Hypocapnia. N Engl J Med. 2009;347:43-53. 